\title{
High-level fed-batch fermentative expression of an engineered Staphylococcal protein A based ligand in E. coli: purification and characterization
}

\author{
Martin Kangwa ${ }^{1}$, Vikas Yelemane ${ }^{1}$, Ayse Nur Polat ${ }^{1}$, Kanaka Durga Devi Gorrepati ${ }^{1}$, Mariano Grasselli ${ }^{2}$
}

and Marcelo Fernández-Lahore ${ }^{1 *}$

\begin{abstract}
The major platform for high level recombinant protein production is based on genetically modified microorganisms like Escherichia coli (E. coli) due to its short dividing time, ability to use inexpensive substrates and additionally, its genetics is comparatively simple, well characterized and can be manipulated easily. Here, we investigated the possibilities of finding the best media for high cell density fermentation, by analyzing different media samples, focusing on improving fermentation techniques and recombinant protein production. Initial fermentation of E. coli BL21 DE3:pAV01 in baffled flasks showed that high cell density was achieved when using complex media, Luria-Bertani (LB) and Terrific medium broth (TB) (10 and $14 \mathrm{~g} / \mathrm{L}$ wet weight, respectively), as compared to mineral media M9, modified minimal medium (MMM) and Riesenberg mineral medium (RM) (7,8 and $7 \mathrm{~g} / \mathrm{L}$, respectively). However, in fed-batch fermentation processes when using MMM after $25 \mathrm{~h}$ cultivation, it was possible to yield an optical density $\left(\mathrm{OD}_{600}\right)$ of 139 corresponding to $172 \mathrm{~g} / \mathrm{L}$ of wet biomass was produced in a $30 \mathrm{~L}$ TV Techfors-S Infors HT fermenter, with a computer controlled nutrient supply (glucose as a carbon source) delivery system, indicating nearly 1.5 times that obtained from TB. Upon purification, a total of $1.65 \mathrm{mg} / \mathrm{g}$ of protein per gram cell biomass was obtained and the purified AviPure showed affinity for immunoglobulin. High cell density fed batch fermentation was achieved by selecting the best media and growth conditions, by utilizing a number of fermentation parameters like media, fermentation conditions, chemical concentrations, $\mathrm{pO}_{2}$ level, stirrer speed, $\mathrm{pH}$ level and feed media addition. It is possible to reach cell densities higher than shake flasks and stirred tank reactors with the improved oxygen transfer rate and feed.
\end{abstract}

Keywords: High cell density, Fed-batch fermentation, Recombinant protein A, E. coli, AviPure

\section{Introduction}

The current high demand, coupled with therapeutic potential of biopharmaceuticals, go hand in hand with the demand in improving industrial biotechnological processes to produce biopharmaceutical molecules of higher quality and quantity. The production of biopharmaceuticals like therapeutic proteins via fermentation

\footnotetext{
*Correspondence: m.fernandez-lahore@jacobs-university.de ${ }^{1}$ Downstream Bioprocessing Laboratory, Department of Life Sciences and Chemistry, Jacobs University, Campus Ring 1, 28759 Bremen, Germany

Full list of author information is available at the end of the article
}

processes is not critical as intensive efforts have been put into their production. For instance, antibody titers in mammalian cell culture has increased drastically over the last decades and currently, it is possible to obtain titers more than $8 \mathrm{~g} / \mathrm{L}$, and protein expression levels higher than $15 \mathrm{~g} / \mathrm{L}$ (Li et al. 2010). However, the mass throughput in biotechnological production plant is limited due to the necessary requirements in the purification of products, in which the costs of production of monoclonal antibodies are mostly defined by the costs of the downstream processing. The most dominating costs is chromatography, filter materials, chemicals and water (Chen et al. 1997; Chin et al. 2015; Glazyrina et al. 2010; Hao

\section{Springer}


et al. 2013). Thus, innovative solutions and technologies in regard to production times, costs and resources have to be developed.

Monoclonal antibodies are attractive tools to develop therapeutics due to their multiple applications. They are among the most promising compounds on the market and one of the pipelines of pharmaceutical biotechnology (Carter 2011; Kabir 2002). They can be employed in vivo according to their ability to bind specifically to a target molecule. In monoclonal antibody purification, affinity chromatography has commonly been used with Staphylococcal aureus protein A (SpA) as the ligand. Protein A is a type I membrane protein from the bacteria Staphylococcus aureus (Bratkovic et al. 2006; Freiherr von Roman et al. 2014; Jungbauer and Hahn 2004; Tsukamoto et al. 2014), consisting of five domains that have a high affinity for the fragment crystallizable $(\mathrm{Fc})$ region of antibodies (Moks et al. 1986; Pabst et al. 2014; Romagnani et al. 1982). The SpA molecule consists of a single polypeptide chain that folds into helix bundles with a molecular weight of approximately $42 \mathrm{kDa}$. Due to high selectivity and good physiochemical stability protein A is a preferred generic ligand for affinity purification of antibodies and molecules tagged with an antibody Fc region. For this reason the molecule have been used for several immunological, and purification applications (Asenjo and Andrews 2009; Barroso et al. 2014; Boi et al. 2009; Zamolo et al. 2008; Zhang et al. 2015), therefore there is need for high level production of the protein.

The currently used protein production technology is based on genetically modified microorganisms such as Escherichia coli (E. coli) (Shiloach and Fass 2005; Zhang et al. 2004). It is one of the most widely used host cells in recombinant protein production and metabolic engineering, due to its short dividing time, ability to use inexpensive substrates and additionally, the genetics of $E$. coli are comparatively simple, well characterized and can easily be manipulated (Glazyrina et al. 2010; Yee and Blanch 1992).

The achievement of high cell concentrations and the use of recombinant $E$. coli, it is necessary to develop fed-batch strategies and multistage reactor systems for fermentation processes that provide high cell mass productivity and high stability. The high cell concentrations fermentation possess some advantages like, reduced reactor volumes, higher volumetric productivities, less efforts in up and downstream processing, reduced waste water and lower costs of production. Microbial fermentation can be categorized into three major groups: batch, fed-batch, and continuous (Chen et al. 1997; Glazyrina et al. 2012, 2010). Batch processes are suitable for small productions and the equipment is relatively simple compared to other processes. However, reaction conditions changes with time causing problems in precise fermentation processes, but on the other hand provide high production and a better quality product for continuous processes due to constant conditions (Shpigel et al. 2000; Yee and Blanch 1992; Cerrone et al. 2014; Ibrahim and Steinbuchel 2010). Batch processes are more useful for kinetic studies, and require flow control in order to maintain constant conditions (Shiloach and Fass 2005). The disadvantage of this method is that the cultures can be unstable after longer fermentation periods. Fed-batch processes primarily focus on increasing the biomass concentration and thereby increasing the productivity, while minimizing problems encountered in high cell density cultivations, since during microbial growth, nutrients, gasses, and trace elements (if necessary) are added (Freiherr von Roman et al. 2014; Glazyrina et al. 2012, 2010; Hoffmann et al. 2000; Korz et al. 1995; Krause et al. 2010). The volumetric yield of the recombinant product depends on both biomass concentrations and the specific cellular product yield.

In this study we focused on high-level fed-batch fermentative expression of an engineered SpA B domain based ligand in E. coli BL21-DE3 (Novagen, Madison, USA), followed by purification and characterization. Though SpA has five domains with affinity for the Fc region, the molecule shows incapability to simultaneously bind five antibody molecules due to steric hindrance that might be caused by bound antibodies which blocks the access of others to the binding sites. This problem of steric hindrance encountered with SpA can be solved by using an AviPure, a ligand analogue based on the native SpA B domain, with a lower molecular weight of approximately $14 \mathrm{kDa}$, containing two repeats of the $\mathrm{SpA}$ B domain, a histidine tag at the $\mathrm{N}$-terminal for $\mathrm{Ni}-$ NTA based purification and two binding sites (CysteineHistidine) at the C-terminal for the immobilization via epoxy groups to the solid support.

\section{Materials and methods \\ Protein engineering}

AviPure with two domain repeats was designed based on Staphylococcus aureus M0464 SpA B domain (accession number: KT377029) with some modification at the $N$, linker and C-terminal and the codon optimized sequence for expression in E. coli BL21 (DE3) was synthesized by Eurofingenomics (Erlangen, Germany) (Additional file 1: Figure S1). Molecular sub-cloning of AviPure into pET28a (+) was performed. Oligonucleotide primers, Avi-Fw ACT AGC TAG CGG ATC CCT GGC GGA TAA TAA ATT TAA C containing BamHI restriction site and Avi-Rv GAA TTC TGA AGC TTC CTT AGT GGC AAT GGC AAT G containing HindIII restriction site (underlined bases indicate BamHI and HindIII sites, 
respectively) also synthesized by Eurofingenomics (Erlangen, Germany) were used to extract the AviPure gene, while restriction enzymes BamHI-HF and HindIII-HF were purchased from New England Biolab (NEB, USA). The expression vector pET28a (+) was from Novagen (San Diego, CA, USA). AviPure PCR amplification was done using the Phusion ${ }^{\circledR}$ High-Fidelity DNA Polymerase (NEB, USA) consisted of 36 cycles of $94{ }^{\circ} \mathrm{C}$ for $30 \mathrm{~s}$, $60{ }^{\circ} \mathrm{C}$ for $40 \mathrm{~s}$ and $72{ }^{\circ} \mathrm{C}$ for $2 \mathrm{~min}$, and followed by a final extension step at $72{ }^{\circ} \mathrm{C}$ for $5 \mathrm{~min}$, producing PCR gene product of about $407 \mathrm{bp}$. Plasmid pET28a (+) and PCR products were purified using NucleoSpin ${ }^{\circledR}$ Plasmid extraction and NucleoSpin ${ }^{\circledR}$ Gel and PCR Clean-up kit (Macherey-Nagel GmbH and Co. KG, Düren, Germany). The pET28a (+) and amplified AviPure gene product were individually digested (BamHI-HF and HindIII-HF) and ligated to obtain pAV01 with the $\mathrm{N}$-terminal hexahistidine tag that facilitate easy purification via Ni-NTA resin. The obtained expression vector was initially amplified in E. coli TOP10 cells and the correctness of the sequence was verified by analytical restriction digest and DNA sequencing (Eurofins MWG Operon, Ebersberg, Germany). The plasmid pAV01 was later isolated and subsequently transformed into $E$. coli BL21(DE3) cells to obtain the E. coli BL 21 (DE3):pAV01 for target protein expression.

\section{Nucleotide sequence accession numbers}

Gene sequences generated in this study were deposited in GenBank and the accession numbers are KT377029.

\section{Protein expression}

Five different media was analyzed for AviPure production: (1) Luria-Bertani medium broth (LB) (10 g/L bacto-tryptone, $5 \mathrm{~g} / \mathrm{L}$ yeast extract, $5 \mathrm{~g} / \mathrm{L} \mathrm{NaCl}$ ); (2) Terrific medium broth (TB) $(12 \mathrm{~g} / \mathrm{L}$ tryptone, $24 \mathrm{~g} / \mathrm{L}$ yeast extract, 9.4 g/L K $\mathrm{K}_{2} \mathrm{HPO}_{4}, 2.2 \mathrm{~g} / \mathrm{L} \mathrm{KH}_{2} \mathrm{PO}_{4}, 4 \mathrm{~mL} 98 \%$ w/v glycerol); (3) M9 minimal medium (M9) (12.8 g/L $\mathrm{Na}_{2} \mathrm{HPO}_{2}, 3 \mathrm{~g} / \mathrm{L} \mathrm{KH_{2 }} \mathrm{PO}_{4}, 0.5 \mathrm{~g} / \mathrm{L} \mathrm{NaCl}, 2 \mathrm{~g} / \mathrm{L} \mathrm{NH} \mathrm{Nl}_{4} \mathrm{Cl}$, $20 \mathrm{~g} / \mathrm{L}$ glucose, $0.01 \mathrm{~g} / \mathrm{L} \mathrm{CaCl}_{2}, 0.12 \mathrm{~g} / \mathrm{L} \mathrm{MgSO}_{4}, 0.002 \mathrm{~g} / \mathrm{L}$ $\mathrm{FeCl}_{3}$ ); (4) Modified Minimal Medium (MMM) [30 g/L glucose, $1.2 \mathrm{~g} / \mathrm{L} \mathrm{MgSO} 4 \times 7 \mathrm{H}_{2} \mathrm{O}, 13.3 \mathrm{~g} / \mathrm{L} \mathrm{KH}_{2} \mathrm{PO}_{4}, 4 \mathrm{~g} / \mathrm{L}$ $\left(\mathrm{NH}_{4}\right)_{2} \mathrm{HPO}_{4}, 1.7 \mathrm{~g} / \mathrm{L}$ citric acid, $10 \mathrm{~mL}$ of trace metals solution, $100 \mu \mathrm{L}$ thiamine $\mathrm{HCL}(45 \mathrm{mg} / \mathrm{mL})$ ]; (5) Riesenberg Mineral Medium (RMM) $\left(7.8 \mathrm{~g} / \mathrm{L} \mathrm{KH}_{2} \mathrm{PO}_{4}, 2.33 \mathrm{~g} / \mathrm{L}\right.$ $\left(\mathrm{NH}_{4}\right)_{2} \mathrm{PO}_{4}, 10 \mathrm{~g} / \mathrm{L}$ glucose, $0.5 \mathrm{~g} / \mathrm{L}$ citric acid, $1.1 \mathrm{~g} / \mathrm{L}$ $\mathrm{MgSO}_{4} \times \mathrm{H}_{2} \mathrm{O}$, trace element solution, thiamine $\mathrm{HCl}$.

E. coli BL 21 (DE3):pAV01 cells from a glycerol stock were initially plated on LB-agar plate containing appropriate antibiotics and incubated overnight at $37^{\circ} \mathrm{C}$, one single colony was later inoculated into $2 \mathrm{~mL}$ LB medium supplemented with appropriate antibiotics and cultured overnight at $37^{\circ} \mathrm{C}$ with shaking at $225 \mathrm{rpm}$. The overnight culture then centrifuge and re-suspended in appropriate media, was transferred into Erlenmeyer flask containing $1 \mathrm{~L}$ cultures of each media and were incubated at $37^{\circ} \mathrm{C}$, at $225 \mathrm{rpm}$. All media were supplemented with $25 \mathrm{mg} / \mathrm{L}$ final amount of Kanamycin to avoid contaminations. Protein expression was induced by the addition of $1 \mathrm{mM}$ final concentration Isopropyl $\beta$-D-1-thiogalactopyranoside (IPTG) at $\mathrm{OD}_{600}$ 0.5. Samples were taken before and after induction and both the supernatant and the pellets were analyzed in a $15 \%$ SDS-PAGE.

\section{Mini-pilot scale fermentation of AviPure}

For mini-pilot scale fermentation, TB and MMM were used. Initially, overnight cultures supplemented with appropriate antibiotics was prepared in $4 \mathrm{~mL} \mathrm{LB}$, further transferred and cultured to an $\mathrm{OD}_{600}$ of 1.0 in $500 \mathrm{~mL}$ Erlenmeyer flask of either TB or MMM media. The culture was later used to inoculate $9.5 \mathrm{~L}$ of TB and MMM media in a $30 \mathrm{~L}$ TV Techfors-S (Infors HT, Switzerland) fermenter previously sterilized at $121{ }^{\circ} \mathrm{C}$ for $20 \mathrm{~min}$ and cooled to $37{ }^{\circ} \mathrm{C}$, respectively. During fermentation process some parameters were observed due to their importance; the change in $\mathrm{OD}, \mathrm{pH}$, aeration, antifoam, carbon source, agitation. At first the fermentation was run in batch mode with dissolved oxygen level maintained at required saturation $\left(\mathrm{pO}_{2}\right)$ by using filtered air and with stirring speed in cascade mode in order to achieve and keep $\mathrm{pO}_{2}$ level constant. The production of foam was hindered by using $5 \%$ antifoam solution (Sigma Aldrich, Germany) and the cultivation temperature was set at $37{ }^{\circ} \mathrm{C}$. During fermentation, the $\mathrm{pH}$ of the media was maintained at 6.8 using a standard $\mathrm{pH}$ electrode (Mettler Toledo, USA) by the addition of phosphoric acid and liquid ammonia and monitored using the $\mathrm{pH}$ sensor unit. Before switching to fed-batch, the dissolved oxygen was used as a guide of the amount of feed needed (Yee and Blanch 1992), with the DO-stat used to balance the amount of glycerol/glucose needed at a time. Calibrated peristaltic pumps were used to control the feed rate for feed media ( $85 \%$ glucose for MMM) which was determined by the metabolic rate of the culture. During fermentation, sampling of the culture in the medium was performed and analyzed for wet cell weight, and optical density at $600 \mathrm{~nm}$. After $22 \mathrm{~h}$, feed was reduced and protein expression was induced with $1 \mathrm{mM}$ final concentration of IPTG solution. Cultivation was continued further $3 \mathrm{~h}$ till the end of cultivation time. E.coli cells pellets were collected by centrifugation using the Thermo Scientific Contifuge Stratos tabletop centrifuge, having a continuous flow rotor at $16,000 \mathrm{rpm}$, at $4{ }^{\circ} \mathrm{C}$. 


\section{Protein purification}

For AviPure purification, $5 \mathrm{~g}$ biomass (pellets) from the previously mini-pilot scale fermentation was re-suspended in $40 \mathrm{~mL}$ sonication/Wash buffer (50 mM Phosphate Buffer $\mathrm{pH}$ 7.5, $300 \mathrm{mM} \mathrm{NaCl}, 10 \mathrm{mM}$ Imidazole) and $350 \mu \mathrm{L}$ protease inhibitor cocktail mix. Direct sonication was performed for 45 min using amplitude of $90 \%$ and 0.6 cycles; with the beaker containing cell suspension placed in ice/ice cold water and was continuously stirred to keep cool. After sonication, the lysate was centrifuged for $1 \mathrm{~h}$ at 16,000 rpm using a Beckman Coulot Avanti J-E centrifuge to get rid of cell debris. IMAC was used to purify the target protein and a $5 \mathrm{~mL} \mathrm{Ni-NTA}$ column volume was chosen, equilibrated with sonication/wash buffer before loading. After centrifugation, the final $40 \mathrm{~mL}$ supernatant was loaded on the column. UPC-900 Amersham Biosciences AKTA FPLC system was employed for the purification. The elution buffer used was the same as the sonication/wash buffer, but contained a higher imidazole concentration $(250 \mathrm{mM})$. The obtained protein was analyzed by SDS-PAGE following the method of Laemmli.

\section{IgG affinity detection of AviPure via Western blot analysis}

The affinity of the AviPure for IgG was investigated using protein affinity binding. Samples collected during cultivation (before and after induction) were resolved by a $15 \%$ SDS-PAGE gel. Separated proteins were blotted onto nitrocellulose membranes (Whatman, Dassel, Germany) using a wet electro-blotting apparatus (Bio-Rad, USA). To prevent non-specific binding, the free binding sites of the membranes were saturated with $5 \%$ fat free dry milk powder in TTBS (overnight at $4{ }^{\circ} \mathrm{C}$ with gentle agitation). Thereafter, the membrane was thoroughly washed five times, each for $5 \mathrm{~min}$ with $50 \mathrm{~mL}$ TTBS. After each incubation, the membrane was washed in the same way. The Goat anti-protein A polyclonal antibodies HRP conjugate at dilution of 1: 6000 was applied to the membrane, incubated for $1.5 \mathrm{~h}$ at room temperature with gentle agitation. This was followed by washing and the membranes were washed again and the proteins were subsequently visualized with a chemiluminescence kit (ECL) on X-ray film.

\section{Ouchterlony radial immunodiffusion}

To perform this method agar media was prepared by melting $2 \mathrm{~g}$ of agar in $50 \mathrm{~mL}$ buffer solution $(50 \mathrm{mM}$ $\mathrm{PO}_{4}{ }^{-}, 75 \mathrm{mM} \mathrm{NaCl}$ at $\mathrm{pH} 7.5$ ) and diluting with $50 \mathrm{~mL}$ water. $450 \mu \mathrm{L}$ of IgG were added to this solution. Petri dishes were used as plates for the test. Several holes were made in the solid agar solution to inject fractions and standards for comparison. Commercial protein A (Repligen, USA) $(0.5 \mathrm{mg} / \mathrm{mL})$ was used as a standard.

\section{Mass spectrometry}

The purity and characterization of AviPure eluted from SEC was analyzed by mass spectrometry (Bruker Daltonik GmbH) (MALDI-TOF). 2, 5-dihydroxybenzoic acid (DHB) was applied as matrix solution and the Bruker PepMix Calibration Standard (\# 222570, Bruker Daltonics) for the calibration of the instrument. For preparation of the matrix on the AnchorChip the DHB matrix layer method was used (for details see also AnchorChip Manual and Bruker Daltonics product sheets). The Autoflex II software was implemented for the evaluation of samples.

\section{Results}

\section{Protein engineering}

To design the AviPure ligand, the gene fragment coding for the B domains was successfully PCR amplified using the primers producing a PCR gene product of about $407 \mathrm{bp}$, restricted digested and was in frame ligated into pET28a $(+)$ vector to obtain the expression vector pAV01. In the final vector plasmid pAV01, the B domain sequences were arranged in series, and later transformed into E.coli BL21 (DE3) to obtain the engineered E. coli BL21 (DE3):pAV01 that was further used in soluble protein expression.

\section{Mini-pilot scale fermentation of protein A AviPure}

Batch fermentations in baffled flasks (Nalgene) were performed to examine the effects of medium composition on cell growth and biomass production in recombinant E. coli:pAV01. Initially, high density biomass and protein level expression was compared in five different $1 \mathrm{~L}$ shaken culture media to help determine the most favorable media and optimal growth conditions for higher quantity protein and biomass production. During shaking cultivation, increase in cell density was observed in complex media type TB (Table 1), when using the baffled Erlenmeyer flask type. The total protein concentration from the collected $1 \mathrm{~mL}$ cell pellets obtained from the overall cultures was determined using the bicinchoninic acid (BCA) assay from Pierce (Rockford, USA) and protein expression was further analyzed using $15 \%$ SDS-PAGE. From Table 1, the results show high total protein and biomass production in $\mathrm{LB}$ and $\mathrm{TB}$, with $\mathrm{TB}$ producing even higher, while less biomass production was observed in mineral salt media MMM, M9 and RMM. Higher protein content (per gram of cell mass) was observed in complex media containing rich nutrients like yeast extracts than in synthetic media. However, the total protein/biomass ratio for all the media was nearly the same.

Based on the shaking culture results, TB, a complex medium and MMM, a synthetic medium (Table 1) were used in mini-pilot scale fermentation. During 
Table 1 Comparison of different media on total protein and biomass production by E. coli BL21 (DE3)/pAV01

\begin{tabular}{llll}
\hline Media & Total proteins (g/L) & Biomass (g/L) & Total protein/biomass ratio \\
\hline LB & $2.10 \pm 0.12$ & $10.22 \pm 0.27$ & 0.21 \\
Terrific broth & $3.02 \pm 0.25$ & $14.60 \pm 0.95$ & 0.21 \\
M9 minimal medium & $1.40 \pm 0.11$ & $7.45 \pm 0.50$ & 0.19 \\
Modified minimal medium & $1.63 \pm 0.11$ & $8.25 \pm 0.38$ & 0.20 \\
Riesenberg mineral medium & $1.57 \pm 0.07$ & $7.58 \pm 0.33$ & 0.21 \\
\hline
\end{tabular}

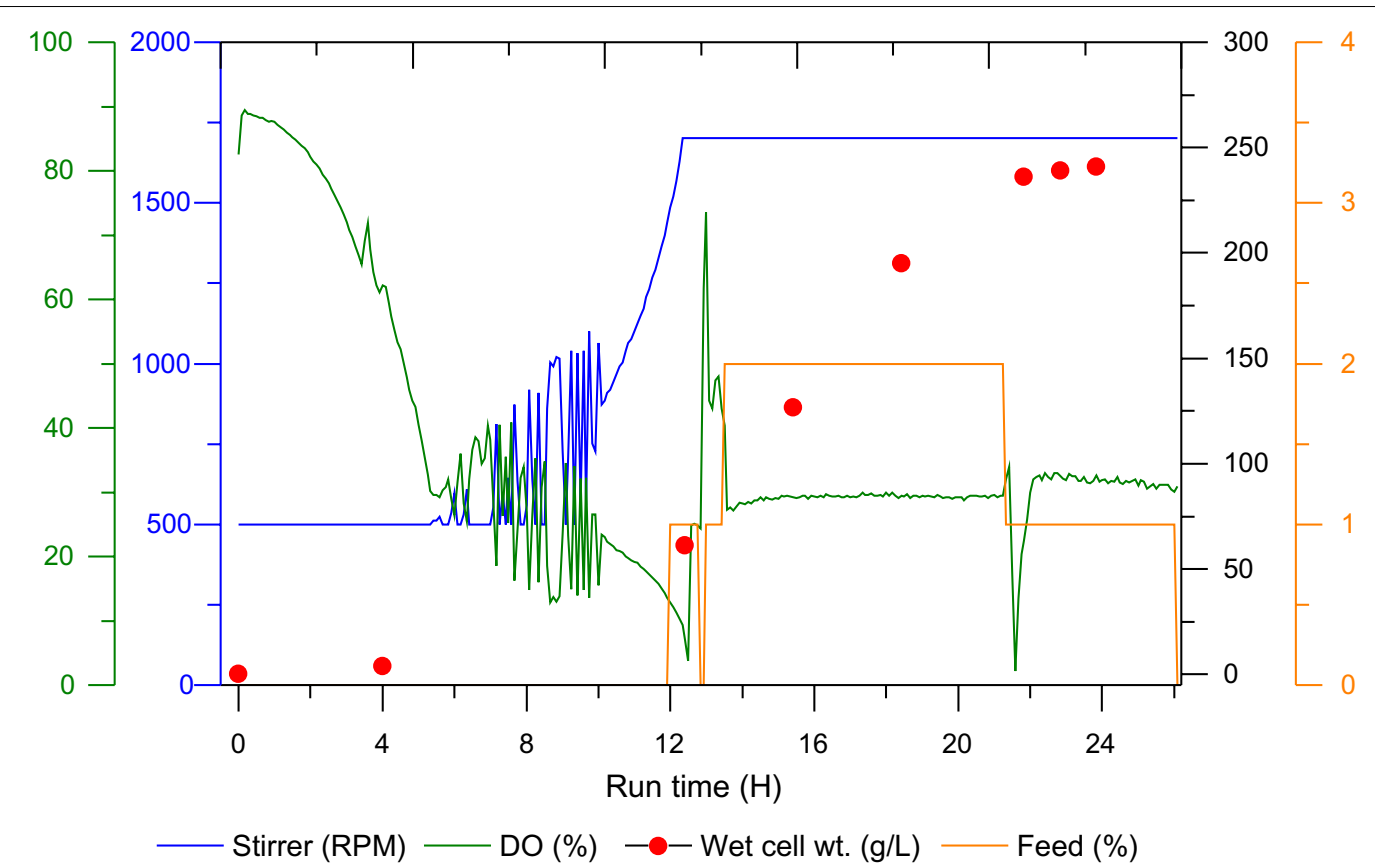

Fig. 1 Optical density (OD) and biomass change in time during fermentation. X-axis shows time in hours. Y-axis at the left side shows stirrer speed (RPM) and dissolved oxygen concentration (\%) and Y-axis at the right side shows biomass accumulation and feed over the time. Accretion of biomass is related with increase of $\mathrm{OD}_{600}$

fermentation, batch culture, then followed by fed batch techniques were used to obtain high cell densities. Biomass production was monitored during cultivation at $\mathrm{OD}_{600}$, and from Fig. 1 it can be observed that the feed rate increased exponentially to maintain a specific growth rate at $37^{\circ} \mathrm{C}$. Feed media (glucose) was added to introduce a carbon source and for the purpose of achieving higher cell density. The feed rate adjustments were done according to observations in the previous shake flask studies. After $22 \mathrm{~h}$ of cultivation, feed was reduced and culture was induced with $1 \mathrm{mM}$ IPTG final concentration for the induction of the T7 promoter-mediated gene expression and for the production of AviPure. From Fig. 1, the relationship between growth rates in time and change in biomass can easily be noticed as the exponential growth phase between
12 and $22 \mathrm{~h}$ is the most remarkable. During fermentation, it was also observed that as the bacterial culture grows $\mathrm{pO}_{2}$ saturation decreases; this was due to the increase in $\mathrm{O}_{2}$ uptake by the culture. To maintain higher $\mathrm{pO}_{2}$ concentration, the stirrer speed was maintained in cascade mode, with the continuously aeration using filter air and by adding feed. Any change in $\mathrm{pO}_{2}$ level combined with a $\mathrm{pH}$ change triggers the $\mathrm{pO}_{2}$ controller. During fermentation, a total of $4800 \mathrm{~g}$ of glucose was used, representing $5.6 \mathrm{~L}$ injected into the fermenter. The final volume after fermentation was about $15 \mathrm{~L}$. After $25 \mathrm{~h}$ of fermentation, product yield of biomass from the media was about 1200 and $2410 \mathrm{~g}$ (wet weight) for TB and MMM, respectively. The dry weight obtained from MMM fermentation was about $52 \mathrm{~g} / \mathrm{L}$. 
During fermentation process they are some characteristic phases which affect the procedure. Therefore, to improve the efficiency and yield in fermentation, manipulation of each phase has an effect on the growth of $E$. coli were observed. In fermentation, change in optical density is related to the growth rate of bacterial cells and the results in Fig. 1, clearly shows the relation between $E$. coli growth rate and change of biomass in which the exponential growth phase is the most remarkable and it shows that the inoculation of the culture medium with resultant growth rate at a specific rate $(\mu)$ increasing from near zero to maximum $\left(\mu_{\max }\right)$. The results show that the exponential phase is characterized by the exponential growth rate at $\mu=\mu_{\max }$ and from the extrapolated results (Fig. 2a, b) shows that the specific growth rate for the exponential phase in our study was around 0.3. Additionally, the cell concentration $\left(c_{\mathrm{x}}\right.$ in $\left.\mathrm{g} / \mathrm{L}\right)$ during fermentation at a given point was calculated by using $\mathrm{OD}=0.54 \times$ biomass, equalize to $\mathrm{OD} / \mathrm{c}_{\mathrm{x}}=0.54$, previously obtained from the trendline in Fig. 2a. $\operatorname{In}\left(c_{x}\right)=\mu_{\max } \times t-a$ was
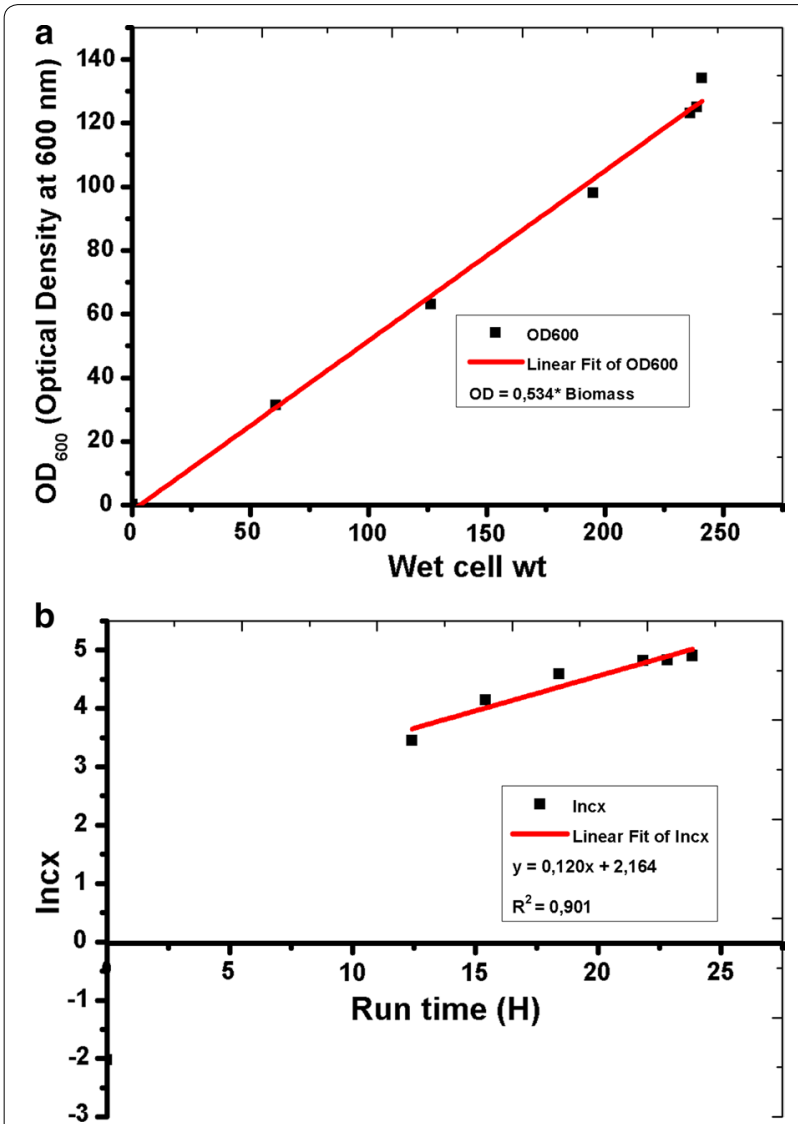

Fig. 2 a Relationship of $\mathrm{OD}_{600}$ to biomass production in E. coli. Linear increase of growth rate is shown in the figure by relating biomass and $\mathrm{OD}_{600}$. b Maximum growth rate calculated by plotting Inc $\mathrm{C}_{\mathrm{x}}$ against time further extracted from the $\ln (\mathrm{cx})$ against the time plot. By using this information, we were able to calculate the starting cell concentration $c_{x, 0}=e^{-a}(\mathrm{~g} / \mathrm{L})$. Maximum growth rate during the exponential phase was found to be $\mu_{\max }=0.45$ (Fig. 2b) and the initial cell concentration is $0.31(\mathrm{~g} / \mathrm{L})$ during fermentation.

\section{Protein purification and SDS-PAGE gel}

Before chromatographic separation, the sonically lysed cells were centrifuged to remove the insoluble particles and the $40 \mathrm{~mL}$ of supernatant was loaded on the Ni-NTA column and the performance of the complete purification process can be seen in Fig. 3a. From the figure, three distinctive stages can clearly be identified. The AviPure elution fractions were pooled, collected and dialyzed. The concentrations of purified protein samples were determined using a Nanodrop 2000c from Thermo Scientific (Wilmington, DE, USA) with the micro volume pedestal and measurement at a wave-length of $280 \mathrm{~nm}$. A total of $1.65 \mathrm{mg} / \mathrm{g}$ of protein per gram cell biomass was obtained and the product had a purity of over $90 \%$ as was further confirmed by $15 \%$ SDS-PAGE with coomassie blue staining (Fig. 3b). The process yield of more than $90 \%$ was achieved, though some bands (impurities) of higher molecular weight than AviPure were visible. Due to this, a second purification step using size exclusion chromatography (SEC) (data not shown) was carried out with the aim of getting rid of the impurities.

\section{Ouchterlony radial immunodiffusion}

Ouchterlony radial immunodiffusion analysis assay (Fig. 4a) was performed to check AviPure (A1 and A2) binding activity with immunoglobulin (Octagam, Australia), while commercial protein $\mathrm{A}$ designated as $\mathrm{R}$ (Repligen, Waltham, MA, USA) was applied as control standard of protein concentration ranging from 5 to $0.1 \mathrm{mg} / \mathrm{mL}$ and each analysis was numbered from 1 to 4 .

After $24 \mathrm{~h}$ of incubation, faint white precipitation rings could be seen on the gels with the naked eye. To amplify these rings, the gel was then stained with Coommassie Blue and the significant dark ring of precipitation is clearly observed, except in well X where BSA was applied.

\section{IgG affinity detection of AviPure via Western blot analysis}

The validity of the purified AviPure was also confirmed by western blot using goat anti-protein A polyclonal antibodies HRP conjugate. The western blot yielded a major band that corresponded to the right molecular weight of the AviPure (Fig. 4b, lanes 3 and 4). No other additional bands were detected by the method, indicating that a pure protein was obtained and no proteolysis occurred during purification and storage. 

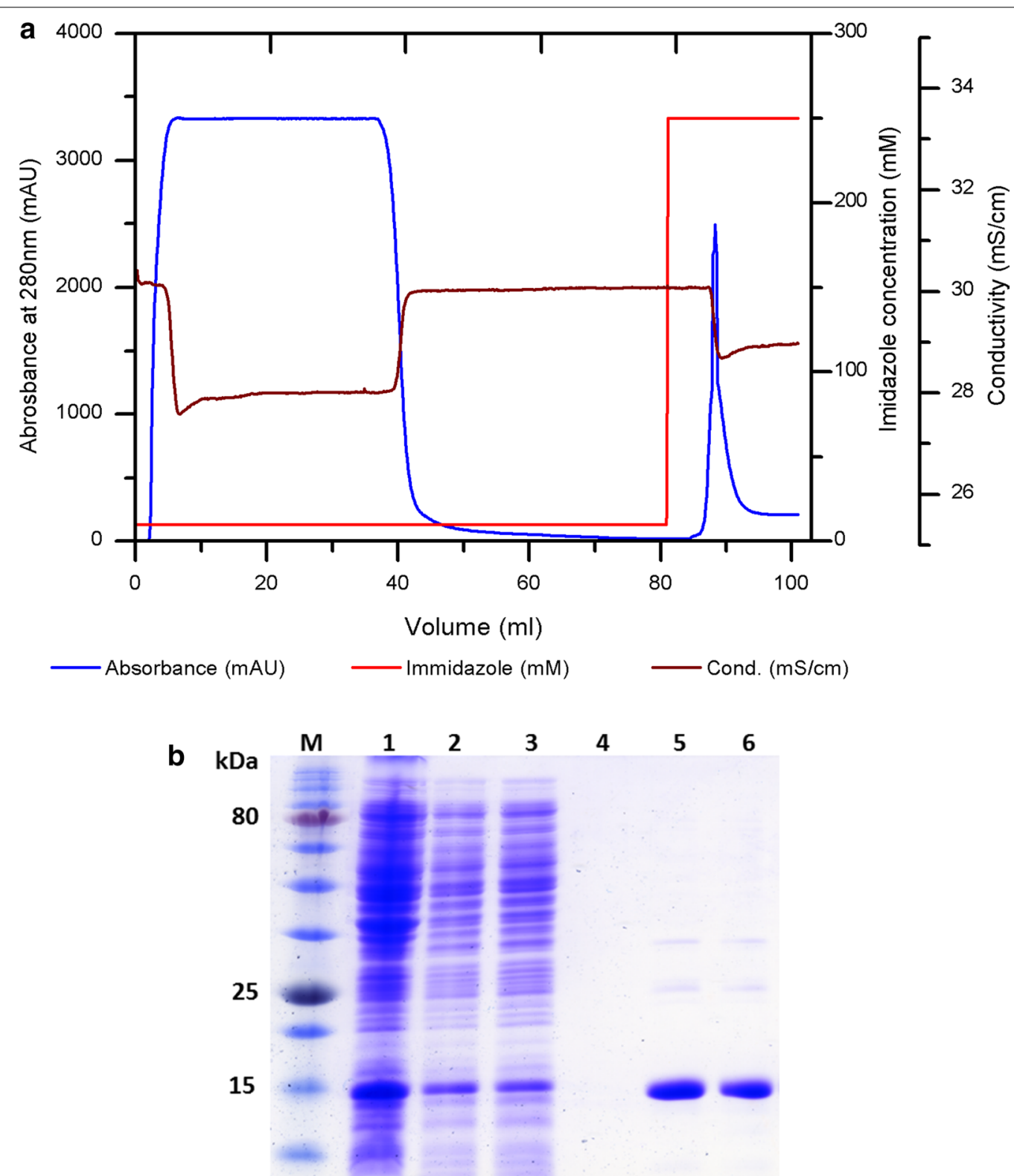

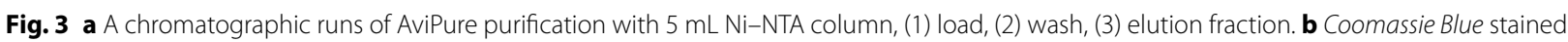
$15 \%$ SDS-PAGE gel from different sample fractions, Lane $M$ represent pre-stained protein marker, Lane 1 induced pellets from culture, Lane 2 supernatant after sonication and centrifugation, Lane 3 flow through, Lane 4 Wash, Lane 5 eluted sample before dialysis, Lane 6 eluted sample after dialysis

\section{Mass spectrometry}

The purified AviPure from SEC showed a single peak in the elution profile fraction, showing that the purity of protein was almost $100 \%$ (Data not shown). In order to investigate SEC results, further analysis of the purified AviPure were conducted by MS MALDI-TOF (Fig. 5) which gave one prominent peak, presenting the AviPure of $14.2 \mathrm{kDa}$, slightly lower than the mass predicted from the DNA sequence of AviPure (15 kDa), but within the error limit of the technique. This peak proves the molecular weight of the purified AviPure, while peaks below 10,000 m/z (mass/charge) represent background noise from the instrument.

\section{Discussion}

Staphylococcus aureus protein A is a highly stable cell surface receptor consists of five domains that have high affinity for the Fc region of IgG and has widely been used mainly in monoclonal antibody purification. In this study, to design the AviPure ligand, we focused on the B domain 

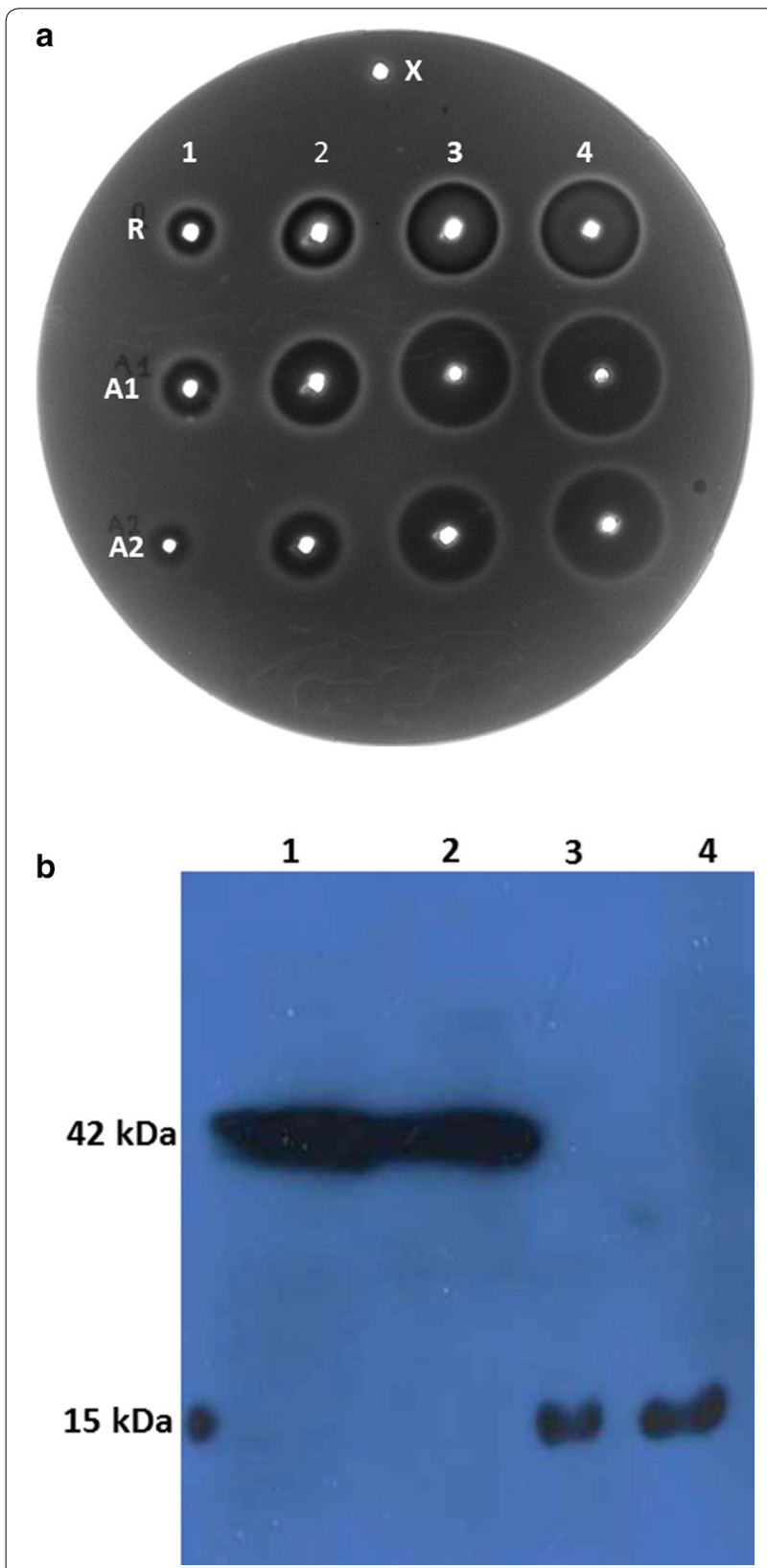

Fig. 4 a Ouchterlony radial immunodiffusion showing crossreactivity of IgG with commercial SpA and purified AviPure. Upper Center well $(X)$ contain BSA. Upper row wells (R1-R5) contain different concentration of commercial SpA (concentration 5, 1, 0.5 and $0.1 \mathrm{mg} / \mathrm{mL}$ ), while middle (A1:1-4) and lower rows (A2:1-4) contain concentration $(5,1,0.5$ and $0.1 \mathrm{mg} / \mathrm{mL}$ ) of purified AviPure. b Western blot analysis of of protein As. Western blot was carried out with Goat anti-protein A polyclonal antibodies HPR conjugate. Lanes 1 and 2; Commercial SpA, Lanes 3 and 4 AviPure eluted from SEC

of SpA, the region having a higher affinity for IgG Fc region (Watanabe et al. 2013) and we were able to demonstrates that the protein can be prepared in high density fed batch fermentation.

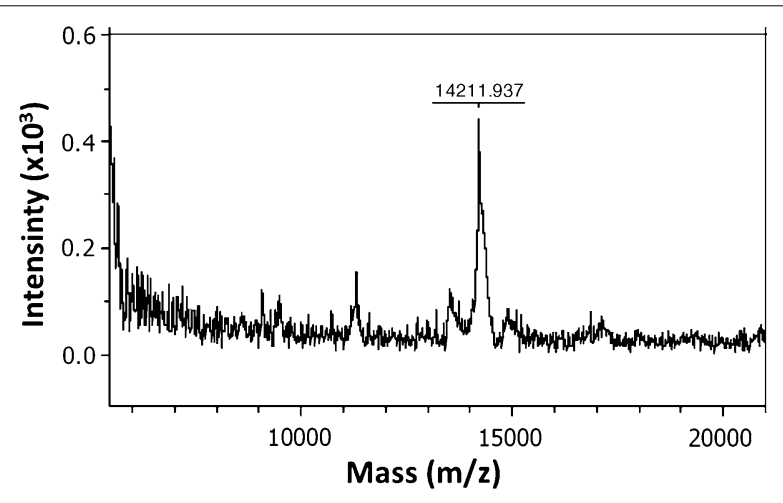

Fig. 5 Identification of AviPure expressed in E. coli by MALDI-TOF. Purified AviPure from size-exclusion chromatography was used for the analyses

During media testing in baffled flasks, it was found that complex media (LB and TB) produced high biomass. In fermentation, media composition is one of the most important parameter that must carefully be considered as cell growth and recombinant product yield depend on it (Shiloach and Fass 2005; Shpigel et al. 2000; Zhang et al. 2004). The cultivation media composition ranges in three major groups: complex, semi complex, and defined. A complex medium contains nutrients which are not well defined chemically e.g., yeast extract, tryptone, peptone, casamino acids, while defined medium consists of chemicals which are chemically defined. Semi defined media is a combination of both complex and defined media nutrients (Panda 2003; Panula-Perala et al. 2008; Schiraldi et al. 2001).

The reason behind high biomass production observed in our batch study when using TB in baffled flasks could have been due to the presence of easy digested yeast extract and tryptone which contains wider varieties of peptides and trace elements, and also due to the glycerol in TB containing a rich carbon source (Schmidt et al. 2005; Eriksen 2008; Sun et al. 2007). On the other hand, fermentation parameters such as specific growth rate could be easily controlled to get a high cell density in the synthetic (mineral) media if carbon rich sources are utilized as fed batch, as can be seen in our results. When mineral salt media is prepared and appropriately supplemented with necessary ingredients, added in the right order and in exact amounts after special sterilization treatments a higher biomass yield production is possible (Freiherr von Roman et al. 2014; Korz et al. 1995; Krause et al. 2010).

During fermentation the $\mathrm{pH}$-stat feeding strategy was used to deal with the issue of glycerol and glucose oscillations based on direct coupling of carbon source consumption and also for the maintenance of related export and import of proton and ammonium ion by the 
cell during growth. While $\mathrm{pH}$ drops by export of $\mathrm{H}^{+}$and import of $\mathrm{NH}_{4}{ }^{+}$from the cells to the media by consuming a carbon source, $\mathrm{pH}$ increases by import of $\mathrm{H}^{+}$and export of $\mathrm{NH}_{4}{ }^{+}$from the cells when the carbon source is exhausted. Although glucose has been used for $\mathrm{pH}-$ stat feeding in many fermentation processes, in this study, glycerol and glucose were preferred for high density culture of E. coli by pH-stat (Shimizu 2013; García-Arrazola et al. 2005).

Medium composition and growth strategies play the most important role in optimizing high density-cell fermentation processes, as product quality insurance and yield of product are the key issues for large scale fermentations. Process optimization and scale up are aimed to maintain optimum and homogeneous reaction conditions and consequently to minimize stress exposure and enhance metabolic accuracy.

Furthermore, we focused on protein purification and characterization. From the results we can clearly see that the protein was expressed, purified and via western blot, Ouchterlony immunodiffusion assay, the protein maintained its affinity for immunoglobulins.

In this study, high level fed batch fermentation was achieved when using MMM. Several fermentation parameters such as culture growth media, growth conditions and chemical concentrations, $\mathrm{pO}_{2}$ level, stirrer speed, $\mathrm{pH}$ level and feed media addition were optimized for high density biomass production. The conditions made it possible to culture cells up to $172 \mathrm{~g} / \mathrm{L}$ wet biomass, (52 g/L dry mass) in $25 \mathrm{~h}$, though Nakano et al. were able to reach cell concentrations of up to 190 and $180 \mathrm{~g} / \mathrm{L}$ dry cell weight after $30 \mathrm{~h}$ fermentation in glucose and glycerol medium (Nakano et al. 1997), respectively. From the reference, the result shows that it possible to obtain higher biomass if continuous feed of carbon source and oxygen available. The final yield of purification process was 1.6 milligrams of AviPure per gram biomass a remarkable result when compared to current literature was achieved. Activity and molecular structures were checked with suitable methods as described before. Results of the characterization experiment showed that after purification steps only a single monomer with a size of $14.2 \mathrm{kDa}$ was present.

The next step is to further characterize and determine the potential application of AviPure for the capture of Immunoglobulin.

\section{Additional file}

Additional file 1: Figure S1. DNA nucleotide sequence for Avipure (underlined). Start codons is indicated in bold. Stop codon is highlighted in red.

\section{Authors' contributions}

MK designed the work. DK help in the sub-cloning and selecting of transformants. MK, ANP, VY carried out the experiments. MK analyzed the data and contributed for the statistical analysis. MK, MG, MFL wrote the manuscript and reviewed the manuscript critically. All the authors read the article and approved the final manuscript.

\section{Author details}

${ }^{1}$ Downstream Bioprocessing Laboratory, Department of Life Sciences and Chemistry, Jacobs University, Campus Ring 1, 28759 Bremen, Germany. ${ }^{2}$ Laboratorio de Materiales Biotecnológicos (LaMaBio), Universidad Nacional de Quilmes-IMBICE (CONICET), Roque Sáenz Peña 352, B1876BXD Bernal, Argentina.

\section{Acknowledgements}

Partial support for this study was provided from Project PGSYS-EXCHANGE EU-PIRSES\#269211, ERA Net Euro TransBio-3, PGYSYS and and Intenso project by European Union Seventh Framework Programme (FP7/2007-2013) under Grant agreement no. 312004.

\section{Competing interests}

The authors declare that they have no competing interests.

Received: 5 August 2015 Accepted: 22 October 2015

Published online: 10 November 2015

\section{References}

Asenjo JA, Andrews BA (2009) Protein purification using chromatography: selection of type, modelling and optimization of operating conditions. J Mol Recognit 22:65-76

Barroso T, Branco RJ, Aguiar-Ricardo A, Roque AC (2014) Structural evaluation of an alternative protein A biomimetic ligand for antibody purification. J Comput Aided Mol Des 28:25-34

Boi C, Busini V, Salvalaglio M, Cavallotti C, Sarti GC (2009) Understanding ligand-protein interactions in affinity membrane chromatography for antibody purification. J Chromatogr A 1216:8687-8696

Bratkovic T, Berlec A, Popovic T, Lunder M, Kreft S, Urleb U, Strukelj B (2006) Engineered staphylococcal protein A's IgG-binding domain with cathepsin L inhibitory activity. Biochem Biophys Res Commun 349:449-453

Carter PJ (2011) Introduction to current and future protein therapeutics: a protein engineering perspective. Exp Cell Res 317:1261-1269

Cerrone F, Duane G, Casey E, Davis R, Belton I, Kenny ST, Guzik MW, Woods T, Babu RP, O'Connor K (2014) Fed-batch strategies using butyrate for high cell density cultivation of Pseudomonas putida and its use as a biocatalyst. Appl Microbiol Biotechnol 98:9217-9228

Chen W, Graham C, Ciccarelli RB (1997) Automated fed-batch fermentation with feed-back controls based on dissolved oxygen (DO) and $\mathrm{pH}$ for production of DNA vaccines. J Ind Microbiol Biotechnol 18:43-48

Chin YW, Kim JY, Lee WH, Seo JH (2015) Enhanced production of 2'-fucosyllactose in engineered Escherichia coli BL21star (DE3) by modulation of lactose metabolism and fucosyltransferase. J Biotechnol 210:107-115

Eriksen NT (2008) Production of phycocyanin - a pigment with applications in biology, biotechnology, foods and medicine. Appl Microbiol Biotechnol $80: 1-14$

Freiherr von Roman M, Koller A, von Ruden D, Berensmeier S (2014) Improved extracellular expression and purification of recombinant Staphylococcus aureus protein A. Protein Expr Purif 93:87-92

García-Arrazola R, Siu SC, Chan G, Buchanan I, Doyle B, Titchener-Hooker $\mathrm{N}$, Baganz F (2005) Evaluation of a pH-stat feeding strategy on the production and recovery of Fab' fragments from E. coli. Biochem Eng J 23:221-230

Glazyrina J, Materne EM, Dreher T, Storm D, Junne S, Adams T, Greller G, Neubauer $P$ (2010) High cell density cultivation and recombinant protein production with Escherichia coli in a rocking-motion-type bioreactor. Microb Cell Fact 9:42

Glazyrina J, Krause M, Junne S, Glauche F, Storm D, Neubauer P (2012) Glucose-limited high cell density cultivations from small to pilot plant 
scale using an enzyme-controlled glucose delivery system. N Biotechnol 29:235-242

Hao J, Xu L, He H, Du X, Jia L (2013) High-level expression of Staphylococcal protein $\mathrm{A}$ in Pichia pastoris and purification and characterization of the recombinant protein. Protein Expr Purif 90:178-185

Hoffmann F, Schmidt M, Rinas U (2000) Simple technique for simultaneous on-line estimation of biomass and acetate from base consumption and conductivity measurements in high-cell density cultures of Escherichia coli. Biotechnol Bioeng 70:358-361

Ibrahim MH, Steinbuchel A (2010) High-cell-density cyclic fed-batch fermentation of a poly (3-hydroxybutyrate)-accumulating thermophile, Chelatococcus sp. strain MW10. Appl Environ Microbiol 76:7890-7895

Jungbauer A, Hahn R (2004) Engineering protein A affinity chromatography. Curr Opin Drug Discov Devel 7:248-256

Kabir S (2002) Immunoglobulin purification by affinity chromatography using protein A mimetic ligands prepared by combinatorial chemical synthesis. Immunol Invest 31:263-278

Korz DJ, Rinas U, Hellmuth K, Sanders EA, Deckwer WD (1995) Simple fedbatch technique for high cell density cultivation of Escherichia coli. J Biotechnol 39:59-65

Krause M, Ukkonen K, Haataja T, Ruottinen M, GlumoffT, Neubauer A, Neubauer P, Vasala A (2010) A novel fed-batch based cultivation method provides high cell-density and improves yield of soluble recombinant proteins in shaken cultures. Microb Cell Fact 9:11

Li F, Vijayasankaran N, Shen AY, Kiss R, Amanullah A (2010) Cell culture processes for monoclonal antibody production. MAbs 2:466-479

Moks T, Abrahmsen L, Nilsson B, Hellman U, Sjoquist J, Uhlen M (1986) Staphylococcal protein A consists of five lgG-binding domains. Eur J Biochem 156:637-643

Nakano K, Rischke M, Sato M, Märkl H (1997) Influence of acetic acid on the growth of Escherichia coli K12 during high-cell-density cultivation in a dialysis reactor. Appl Microbiol Biotechnol 48:597-601

Pabst TM, Palmgren R, Forss A, Vasic J, Fonseca M, Thompson C, Wang WK, Wang X, Hunter AK (2014) Engineering of novel Staphylococcal protein A ligands to enable milder elution $\mathrm{pH}$ and high dynamic binding capacity. J Chromatogr A 1362:180-185

Panda AK (2003) Bioprocessing of therapeutic proteins from the inclusion bodies of Escherichia coli. Adv Biochem Eng Biotechnol 85:43-93

Panula-Perala J, Siurkus J, Vasala A, Wilmanowski R, Casteleijn MG, Neubauer P (2008) Enzyme controlled glucose auto-delivery for high cell density cultivations in microplates and shake flasks. Microb Cell Fact 7:31
Romagnani S, Giudizi MG, del Prete G, Maggi E, Biagiotti R, Almerigogna F, Ricci M (1982) Demonstration on protein A of two distinct immunoglobulinbinding sites and their role in the mitogenic activity of Staphylococcus aureus Cowan I on human B cells. J Immunol 129:596-602

Schiraldi C, Acone M, Giuliano M, Di Lernia I, Maresca C, Carteni M, de Rosa M (2001) Innovative fermentation strategies for the production of extremophilic enzymes. Extremophiles 5:193-198

Schmidt RA, Wiebe MG, Eriksen NT (2005) Heterotrophic high cell-density fed-batch cultures of the phycocyanin-producing red alga Galdieria sulphuraria. Biotechnol Bioeng 90:77-84

Shiloach J, Fass R (2005) Growing E. coli to high cell density - a historical perspective on method development. Biotechnol Adv 23:345-357

Shimizu K (2013) Regulation systems of bacteria such as Escherichia coli in response to nutrient limitation and environmental stresses. Metabolites 4:1-35

Shpigel E, Goldlust A, Eshel A, Ber IK, Efroni G, Singer Y, Levy I, Dekel M, Shoseyov O (2000) Expression, purification and applications of staphylococcal protein A fused to cellulose-binding domain. Biotechnol Appl Biochem 31(Pt 3):197-203

Sun Z, Ramsay JA, Guay M, Ramsay BA (2007) Carbon-limited fed-batch production of medium-chain-length polyhydroxyalkanoates from nonanoic acid by Pseudomonas putida KT2440. Appl Microbiol Biotechnol 74:69-77

Tsukamoto M, Watanabe H, Ooishi A, Honda S (2014) Engineered protein A ligands, derived from a histidine-scanning library, facilitate the affinity purification of IgG under mild acidic conditions. J Biol Eng 8:15

Watanabe H, Matsumaru H, Ooishi A, Honda S (2013) Structure-based histidine substitution for optimizing $\mathrm{pH}$-sensitive Staphylococcus protein A. J Chromatogr B Analyt Technol Biomed Life Sci 929:155-160

Yee L, Blanch HW (1992) Recombinant protein expression in high cell density fed-batch cultures of Escherichia coli. Biotechnol NY 10:1550-1556

Zamolo L, Busini V, Moiani D, Moscatelli D, Cavallotti C (2008) Molecular dynamic investigation of the interaction of supported affinity ligands with monoclonal antibodies. Biotechnol Prog 24:527-539

Zhang Y, Shen YL, Xia XX, Sun AY, Wei DZ, Zhou JS, Zhang GJ, Wang LH, Jiao BH (2004) High-cell density cultivation of recombinant Escherichia coli for production of TRAIL by using a 2-stage feeding strategy. Sheng Wu Gong Cheng Xue Bao 20:408-413

Zhang S, Xu K, Daniels W, Salm J, Glynn J, Martin J, Gallo C, Godavarti R, Carta G (2015) Structural and functional characteristics of virgin and fouled protein A MabSelect resin cycled in a monoclonal antibody purification process. Biotechnol Bioeng

\section{Submit your manuscript to a SpringerOpen ${ }^{\odot}$ journal and benefit from:}

- Convenient online submission

- Rigorous peer review

- Immediate publication on acceptance

- Open access: articles freely available online

- High visibility within the field

- Retaining the copyright to your article

Submit your next manuscript at $>$ springeropen.com 